\title{
Depressed Older Patients' Need for and Expectations of Improved Health Services -An Evaluative Approach to the Chronic Care Model
}

\author{
Anne Lyberg ${ }^{*}$, Ingela Berggren ${ }^{2}$, Anne Lise Holm³ ${ }^{3}$, Elisabeth Severinsson ${ }^{1}$ \\ ${ }^{1}$ Centre for Women's, Family and Child Health, Faculty of Health Sciences, Buskerud and Vestfold University \\ College, Kongsberg, Norway \\ ${ }^{2}$ Department of Nursing, Health and Culture, University West, Trollhättan, Sweden \\ ${ }^{3}$ Department of Health Science, Stord/Haugesund University College, Stord, Norway \\ Email: ${ }^{*}$ anne.lyberg@hbv.no
}

Received 23 March 2015; accepted 21 April 2015; published 24 April 2015

Copyright (C) 2015 by authors and Scientific Research Publishing Inc.

This work is licensed under the Creative Commons Attribution International License (CC BY).

http://creativecommons.org/licenses/by/4.0/

(c) (i) Open Access

\begin{abstract}
Depression in later life is an underrepresented yet important research area. The aim of the study was to explore depressed older persons' need for and expectations of improved health services one year after implementation of the Chronic Care Model (CCM). A qualitative evaluative design was used. Data were collected through individual interviews with older persons living in Norway. The qualitative content analysis revealed two themes: The need to be safeguarded and Expectation of being considered valuable and capable. Evaluation of the improvement in care with focus on the CCM components showed that the most important components for improving the depressed older person's daily life were: delivery system re-design, self-management support, productive interaction and a well-informed active patient. The findings highlight the need for a health services designed for persons suffering from chronic ill-health, where the CCM could serve as a framework for policy change and support the redesign of the existing healthcare system. We conclude that older persons with depression need attention, especially those who have been suffering for many years. The identified components may have implications for health professionals in the promotion of mental healthcare.
\end{abstract}

\section{Keywords}

Chronic Care Model, Depression, Expectations, Health Services, Needs, Older Persons

\footnotetext{
${ }^{*}$ Corresponding author.
}

How to cite this paper: Lyberg, A., Berggren, I., Holm, A.L. and Severinsson, E. (2015) Depressed Older Patients' Need for and Expectations of Improved Health Services-An Evaluative Approach to the Chronic Care Model. Open Journal of Nursing, 5, 376-386. http://dx.doi.org/10.4236/ojn.2015.54041 


\section{Introduction}

Mental health conditions, such as depression, have been largely overlooked as a target for development work [1]. The WHO [2] has projected that depression will be a leading cause of disability in all countries by 2020. People suffering from depression are vulnerable and therefore require support and treatment [1]. This is particularly true of older adults, as they are less likely than their younger counterparts to be identified and treated [3]. Even when identified, depression is frequently dismissed as a natural reaction to a person's life situation [4]. Despite the fact that effective pharmacological and psychological treatment is available, however the outcome of routine care is generally poor [5]. Research in the US has demonstrated that up to $80 \%$ of older adults receiving treatment for depression in primary care settings fail to improve [6]. Moreover, clinical, attitudinal, patient and organizational barriers can hinder the recognition of depression as well as effective treatment. The overlap of somatic symptoms of depression, such as fatigue and loss of appetite, with symptoms of physical illness and the side effects of medication can often lead to diagnostic uncertainty, while the core symptom of sadness is frequently absent or reduced in depressed elderly people [4]. The most common risk factors for depression are; female gender, somatic illness, cognitive reduction, stroke, lack or loss of close social contacts, earlier depressive episodes, being a widow, needing help in daily life, stressful life situations, poor financial status and depression inducing drugs [7].

\subsection{Older Depressed Patients' Experiences of Their Daily Life}

Robinson et al. [8] presented four themes describing patients' and relatives' experiences of mental illness: stigma, shame, isolation and being ignored, which resulted in reluctance to seek care and thus failure to receive the necessary treatment. This is underpinned by the findings of Holm et al. [9] describing depressed older persons with psychical health problems and their experiences of stigma. Furthermore, Robinson et al. [8] highlighted practical barriers to accessing mental healthcare, such as the distance to specialist mental healthcare centres and associated costs. The depressed older persons also felt discouraged and in some cases experienced hopelessness. They believed that no one in the community would act as an advocate for them and therefore had to be their own advocate. This is in line with the findings of Zeng et al. [10], where depressed older persons described negative thinking as central to their lived experiences. Feelings of uselessness, hopelessness, sadness and helplessness were expressed. They had a negative view of themselves, their experiences and the future. Allan \& Dixon [11] found it of fundamental importance for depressed older women that other people tried to understand them, as being met with understanding enabled them to try to connect with other people. Lack of such understanding made them hide from the world, which increased their loneliness and sense of isolation. Depressed older people have reported a constant deep longing for a closer relationship with family members [12].

In a secondary analysis of previous qualitative interview data with focus on the question of why older people with depression do not present to primary care, some expressed that they would not turn to their general practitioner (GP) when feeling depressed, as she/he is very busy and only prescribes medication. Their previous experience of seeking help in primary care had been negative, as the care provided failed to address the social aspects of their life, particularly the problem of isolation. They wanted interventions that promoted physical and social activity [13].

\subsection{The Chronic Care Model}

Despite the difficulties referred to above, there is increasing recognition that treatment for depression can be improved. The challenge for countries is not simply to scale up existing health services, but to transform health systems by implementing evidence-based approaches to enable integrated, effective and efficient care for mental disorders such as depression and other chronic diseases [1]. Implementation is defined as a specific set of activities designed to put an activity or programme of known dimensions into practice. It includes dissemination, surveillance, monitoring and long term follow up [14]. The Chronic Care Model (CCM) has been adopted by the WHO [15] and applied successfully in the treatment of chronic conditions [16] [17]. The model is a quality improvement and service redesign strategy developed by Wagner and colleagues [18]. The thinking that underpins the CCM is that present healthcare systems constitute the main barrier to the effective treatment of long term conditions. These systems have evolved to support the management of acute and episodic illness and, although necessary, are inadequate for dealing with long-term conditions. The CCM framework of conceptualises care as 
provided by prepared practice teams in productive interactions with well-informed, active patients. Interactions can be productive when patients are active, well-informed and participate in their own care, for which they require the information, skills and confidence to make the best use of their involvement with the healthcare team. The CCM emphasizes the importance of six interlinked areas that need to be addressed in order to improve the organization of care for patients with long-term conditions: self-management support (helping the patient and her/his family to acquire the skills and confidence to manage everyday life); clinical information systems (how to provide information and clinical care); delivery system re-design (creating healthcare teams with clear responsibility); decision support (providing optimal care at the right time); the healthcare organization and linkages to community based resources (e.g., exercise programmes, senior citizen and self-help groups). The model has a practical focus and can be adapted to different organizational contexts [16]-[18]. This study was part of a larger project entitled "Chronic Disease Management-Implementation and coordination of healthcare systems for depressed elderly persons in Norway”. The project comprised three parts (i.e., exploration, implementation and evaluation) and three specific objectives were formulated: (1) To identify depressed elderly persons’ subjective experiences of depression and the healthcare system [19]-[21], (2) To implement the CCM model in interdisciplinary healthcare teams [22]-[24] and (3) To evaluate the quality of care provided in relation to the components of the CCM [25]-[27].

\subsection{Aim}

The aim of the study was to explore depressed older persons' need for and expectations of improved health services one year after implementation of the Chronic Care Model.

\section{Methods}

\subsection{Design}

In this follow-up study a qualitative evaluative design was used to interpret older persons' narratives of their needs, as well as expectations of improved health services one year after implementation of the CCM [28].

\subsection{Participants}

The participants comprised two men and seven women. They were selected from a sample of 29 older persons from the west coast and the south eastern part of Norway, who had been interviewed in 2012 [12] [19]. The inclusion criteria were persons aged over 60 years who had been diagnosed with a long term depressive or mood disorder, living in their own home and receiving ongoing formal support from primary healthcare during the previous six months. Participants who proved to be good narrators of their needs as well as expectations of the health services in the first interview were asked by the first (AL) or third (ALH) author if they would be willing to participate on a second occasion, one year after implementation of the CCM. The researchers decided in advance to include ten participants in the second interview. They made a list of ten persons who expressed an interest, which they gave to the nurses who had recruited the participants on the first occasion. The nurses phoned those on the list to ensure that they would have no objection to being contacted by the researchers. None of the potential participants declined to participate in the second interview. However, one participant had to withdraw because of somatic illness, hence the researchers decided to continue with a sample of nine. The participants (mean age 65 years) were interviewed in their own homes or at the researchers' offices. Two suffered from bipolar disorder, while seven had been diagnosed with depression. Two were widows and seven were divorced.

\subsection{Data Collection}

Data were collected in 2013 by means of individual interviews that took the form of a dialogue. The interviewers encouraged the participants to narrate whether they had experienced improvements in the care and to describe their needs as well as their expectations of the health services. The interviews, which were audio-taped and transcribed verbatim, lasted between 60 and 120 minutes.

\subsection{Qualitative Content Analysis}

Qualitative content analysis focused the content of text and can be applied to a variety of data [29]. According to 
Graneheim and Lundman [30], qualitative content analysis makes a distinction between manifest, i.e., a descriptive level, and latent analysis, which means various depths of interpretation. In this study a descriptive analysis was used in order to present the older persons' needs and expectations of the health services one year after implementation of the CCM. In the qualitative content analysis the transcripts were first read several times to become familiar with the text. Then meaning units, based on the depressed older persons' need for and expectations of the health services, were identified and condensed in order to reduce the number of words while preserving the core content. In the next step the condensed meaning units were labelled with a code. The codes were grouped together to form subthemes and themes [29] [30] (Table 1).

\subsection{Rigour}

As this study has a qualitative methodology, it is important to establish trustworthiness [31], for which various strategies exist [32]. The checklist presented by Elo et al. [33] to improve trustworthiness in qualitative research was taken into consideration at every phase of the analysis process, including the preparation, organization and reporting of results. To ensure validity the authors repeatedly discussed the emerging sub-themes and themes as well as the comprehensive interpretation throughout the analysis process in an attempt to provide a deeper understanding of depressed older persons' narratives of their needs and expectations of the health services.

\subsection{Ethical Issues}

The study was approved by The Regional Ethics Committee of Western Norway (No. 2010/2242). Approval was also granted by the nurse managers in the communities where the participants received health services. The ethical procedures specified in the declaration of Helsinki [34] were adhered to. The researchers were trained to deal with and respond to sensitive issues. They tried to interpret the participants' expressions and non-verbal signs to ascertain whether they were capable of discussing their experiences or whether the topic was too sensitive. As the researchers are responsible for the participants' safety and security, referral to healthcare was available if required. The participants were invited to contact a named professional if they felt in any way upset after the interviews [35]. The participants were provided with oral and detailed written information and signed a consent form. They were assured that their name and identity would not be disclosed and that they had the right to withdraw at any time. They were also informed that the audio-recordings and transcripts would be destroyed at the end of the project. All data were stored in a locked and fireproof filing cabinet.

\section{Results}

The depressed older persons' narratives about what they need and expect from the health services one year after implementation of the CCM with focus on perceived improvement in care were interpreted and formulated into two themes: The need to be safeguarded and Expectation of being considered valuable and capable. The first theme, The need to be safeguarded comprised four sub-themes; The need for a coordinator, Access to specialist psychiatric care, Learning skills to better deal with problems and Support to address emotional pain. The second theme, Expectation of being considered capable and valuable was based on the following sub-themes; Being taken seriously, Being involved in decision-making and Experiences of trust and hope.

The need for improved health services in relation to the CCM showed that the component Delivery system redesign was linked to The need to be safeguarded, The need for a coordinator and Assess to specialist psychiatric care. The component Self-management support comprised Learning skills to better deal with problems and Support to address emotional pain, as well as Experiences of trust and hope. The theme of Expectation of being considered capable and valuable and the sub-themes Being taken seriously and Being involved in decisionmaking were interpreted as belonging to the components Productive interactions, where patients are well-informed

Table 1. An example of the qualitative content analysis.

\begin{tabular}{llll}
\hline Meaning unit & Condensed meaning unit & Code & Sub-Theme \\
$\begin{array}{llll}\text { The GP's* prescribed medication } \\
\text { that made me feel as if I was } \\
\text { floating and walking on clouds.... }\end{array}$ & $\begin{array}{l}\text { An unpleasant feeling and } \\
\text { negative side effects of the } \\
\text { medication }\end{array}$ & $\begin{array}{l}\text { Insecurity about whether } \\
\text { the medication is correct }\end{array}$ & $\begin{array}{c}\text { Refereed to } \\
\text { specialist } \\
\text { psychiatric care }\end{array}$ \\
\hline
\end{tabular}

${ }^{*}$ General Practitioner. 
and active and participate in their care with Decision support from the healthcare team. Productive interactions such as information systems enhanced patients' and family members’ ability to become involved (Table 2).

\subsection{The Need to Be Safeguarded}

The participants' perception of their need for improved care was related to the feeling of insecurity and being alone with their health problems. For many it was an ongoing struggle to receive essential help. Above all, they complained about the lack of continuity and availability of services they considered vital for their health.

\subsubsection{The Need for a Coordinator}

Some of the participants were followed up by a community psychiatric nurse who usually provided home visits. A few received a visit every fortnight, but in most cases the interval between the visits was much longer. The content of the visit usually consisted of talking about what had happened since the previous meeting. Some of the participants were satisfied with the service but most considered that the nurse did not play an important role, as she did not coordinate the services and was not available when needed. Some of the nurses left a telephone number by which they could be contacted, while others did not do so and some did not even have a mobile.

"Once I was very sad and felt so lonely. I tried to phone my psychiatric nurse, but she was busy. I left a message on her answering machine. She did not phone back, nothing happened.” (Woman E)

Another participant narrated a situation of how she realised that she was about to enter a state of psychosis. She phoned her general practitioner (GP) but he was unable to give her an appointment that day, so she went to emergency primary care, but the severity of her condition was not understood and she was refused help.

"In the end I was so desperate that when I saw that the church door was open I went inside hoping to find the vicar. Perhaps he would understand my need for help-but it was a choir practice. I also called a healer without success. It ended when the police found me naked on the church steps and took me to hospital.” (Woman F)

At the time of the first interview none of the participants had a coordinator appointed by the health service. When nine of the participants were interviewed a year later, one had recently been offered a coordinator and was relieved because the health services were going to build a team to support her.

"After struggling alone for ten years I will finally get help. We had a meeting with representatives from specialist healthcare and the community. They appointed a coordinator and made a care plan to address my needs. My coordinator will be like "an army commander". I hope I will get more suitable housing and help to become more active. The best of all is having someone I can contact who will ensure my GP and psychiatrist cooperate about my medication.” (Woman F)

\subsubsection{Access to Specialist Psychiatric Care}

GPs prescribed psychotropic drugs for the depressed elderly persons and monitored their effects. There were examples of wrong medication in addition to medication that made one participant feel as if he was; "floating and walking on clouds, it was worse than drinking too much alcohol”. (Man I). A majority of the participants were satisfied with their own GP, as some GPs were interested in mental health problems and saw the participants

Table 2. Older persons' needs as well as expectations of improved health services in relation to the components of the Chronic Care Model (CCM).

\begin{tabular}{ll}
\hline Older persons' need as well as expectations for improved health services & The CCM components \\
Theme 1: The need to be safeguarded & Delivery system re-design \\
Sub-themes: & \\
The need for a coordinator & Delivery system re-design \\
Access to specialist psychiatric care & Delivery system re-design \\
Learning skills to better deal with problems & Self-management support \\
Support to address emotional pain & Self-management support \\
Theme 2: Expectation of being considered capable and valuable & Productive interactions \\
Sub-themes: & \\
Being taken seriously & Well-informed active patient \\
Being involved in decision-making & Well-informed active patient, decision-support \\
Experiences of trust and hope & Self-management support \\
\hline
\end{tabular}


at regular intervals. In most of the interviews the participants complained about the GPs' busy schedule that resulted in a lack of time to listen and become involved in their situation as a whole. Some changed to a new GP when they were not satisfied, although they regarded it as a risk. They doubted that another GP would be better and regarded themselves as her/his least favourite patients.

"I feel just like "a number" in my relationship with the GP." (Man C)

The participants did their best to avoid re-admission to a psychiatric hospital, believing that home was the best place for them and because of negative hospital experiences. Some reported only receiving food and a bed and considered that they were administered too much medication. Worst of all was the feeling that the staff had given up on them due to their long-term health problems. Other patients could also be a burden, as the participants experienced being negatively affected by their suffering. However, there were also examples of understanding as well as recognition of the help they received in hospital.

The participants wanted access to outpatient psychiatric clinics in order to be examined by a psychiatrist, correctly diagnosed and prescribed appropriate medication. They did not expect such consultations on a regular basis, only when the primary care did not lead to an improvement. They were of the opinion that depressed older individuals did not receive priority.

"My GP referred me to a psychiatrist, but I was not ill enough. If you are not a danger to yourself or others you will not receive such treatment in this country. I could try going private, but with my small pension I cannot afford it.” (Woman G)

One of the participants had mental health problems since she was in her twenties. At the age of sixty-five and after having being admitted to a psychiatric hospital on several occasions, a psychiatrist in an out-patient clinic changed her diagnosis from depressive to bipolar disorder.

"Of course it was not a diagnosis that I wanted, but now I am able to understand the things that have happened in my life. It also give me some rights in relation to the health services." (Woman F)

\subsubsection{Learning Skills to Better Deal with Problems}

The depressed elderly persons wanted to learn how to better deal with their mental health problems. For example, what to do when afflicted by panic attacks or suicidal thoughts. One participant had attended a course on how to cope with depression and found it helpful; "I learnt how thoughts control your perceptions and got to know a lot about myself. Maybe that is why I am feeling better?” (Woman D). The participants also wanted to learn how to deal with interpersonal relationships. Setting boundaries for other people was a recurrent theme in several interviews. They expressed the need to protect themselves from additional burden, as coping with their own problems was difficulties enough. When they were unable or unwilling to listen to other people's problems they felt uncomfortable, which often led to feelings of guilt.

"I feel irritated, especially with certain people at the mental health day centre. I have difficulties setting limits for them. I cannot carry their burdens, but on the other hand I want to be a decent human being.” (Woman B)

Family conflicts were common. During the interviews the participants repeatedly returned to the conflicts that constantly occupied their minds. Being unable to resolve them meant that they were caught in a trap. Many thought there was a connection between these conflicts and their depressive ill-health. There were few experiences of receiving help from healthcare professionals to address the feelings involved in the conflicts, such as guilt, sorrow and anger. Many needed healthcare professionals to act as "go-betweens" in an attempt to encourage family members to remain on speaking terms.

"My very elderly mother and I live together. She has become extremely demanding. I have no privacy and my responsibility for her makes my depression worse. I explained the situation to the primary health service staff and my mother was offered day care once a week. When I mentioned this to my mother she became very angry and refused to consider day care. We said things to each other that I regret. The next day I tried to make it up to her-I took her to a shopping centre and spent the whole day there. My mother was happy, but I was worn out." (Woman E)

\subsubsection{Support to Address Emotional Pain}

The depressed elderly persons’ life stories were filled with traumatic events and losses. The analysis revealed the need to restore their self-respect. Having suffered from mental health problems for years, many of the participants blamed themselves for not being good enough throughout life. There was no systematic psychological support available and many of the participants did not even consider it as a possibility. The quotation below is 
from a man who was recently treated for depression in a psychiatric hospital but was not given an opportunity to describe the thoughts that bothered him.

"I cannot sleep at night because of memories from the war and the torture. I struggle alone to block the memories and prevent them from leaking out. Because of this I am not getting better and experience nothing but despair, fear and emotional pain.” (Man C)

Having nobody with whom to share their problems made the depressed older persons vulnerable. They were accustomed to being ignored by the health services. When someone showed an interest they took advantage of the opportunity, although there was always a risk of being disappointed.

\subsection{Expectation of Being Considered Capable and Valuable}

This theme revealed a desire to be considered capable and valuable. The participants believed that they were doing their best to manage their depressive ill-health and did not take unnecessary advantage of available healthcare. They expected to be respected for their hard work to achieve self-management. However, this was not sufficiently acknowledged and instead they experienced being assessed on the basis of their psychiatric history. In interactions with healthcare professionals they perceived being treated with disinterest. On the other hand, when experiencing productive interactions with healthcare professionals they felt cared for and safe.

\subsubsection{Being Taken Seriously}

The analysis demonstrated that the depressed older persons wanted to be taken seriously and to play an active role in their care, especially in relation to various somatic problems. They experienced that physicians often interpreted somatic problems as part of their depressive ill-health. One participant stated;

"When prescribed psychotropic drugs no one believes you. There is a lot of prejudice and negative attitudes towards us. I have been met like 'a cold winter day' by the health services-I don't know if I can handle more of those days". (Woman $\mathrm{H}$ )

However, there were also examples of the opposite. When involved the participants perceived being taken seriously, which often led to trusting relationships with healthcare professionals.

"When my new GP told me he would not give up until he found the reason for my stomach pain, I was overwhelmed. I have had this stomach pain for years and never experienced such an interest before". (Woman F)

\subsubsection{Being Involved in Decision-Making}

The participants also wanted to be informed and involved in decision-making about their care and treatment, as many of the participants had previously not been allowed to have a say or express their views.

Some of the participants perceived not being involved as an insult. One woman had suffered from an eating disorder for many years without receiving treatment. When the psychiatric services announced a new group therapy programme for people with eating disorders she asked her GP for referral.

"When my referral was rejected I considered it very insulting. I had no opportunity to influence the decision, which was made without knowing me or my problems. I think the reason for refusal was my age." (Woman A)

However, there was also an example of the opposite. One of the participants described a meeting with a psychiatrist as a surprising and fantastic event because of being involved in decision-making. "He listened and included me in decisions. He shared his thoughts and asked for my opinion. Not being overruled was incredible." (Woman F)

\subsubsection{Experiences of Trust and Hope}

The participants had all been severely afflicted with depressive ill-health for many years. This was evident in the interviews by how they presented themselves and described their situation as well as the many ways in which their lack of energy manifested itself. Despite long term ill-health, the analysis revealed a will and hope for a better future. The participants mourned the limitations in their lives as a result of their mental health problems and especially wanted to enjoy the same lifestyle as other people of the same age.

"If only I could be spared the anxiety. Why can't I have peace of mind? I long for the day when I will be able to return to the senior centre again." (Woman $\mathrm{H}$ )

The hope was fragile and on some days they doubted ever experiencing better health. Instead, they feared that their condition would become worse and that they would be unable to manage it by themselves. Access to pro- 
fessionals who trusted and supported them made a difference.

"When I am alone my thoughts begin to spin and become disorganised and dark. In conversations with the nurse I was able to tell her what worried me. I exaggerated it because I have a rich imagination. The nurse got me back on track.” (Man I).

\section{Discussion}

The findings demonstrate that the depressed older persons need to be safeguarded, as they did not succeed in obtaining appropriate healthcare. For many it concerned lack of care, while availability and continuity were problems common to all the participants. Depressive ill-health and the sense of being left on their own made them feel unsafe. A way to create improvement would be to re-design healthcare delivery system [18]. The CCM proposes multidisciplinary care teams with clear responsibility and the appointment of a coordinator, also termed a case manager, for each patient. The coordinator, usually a nurse or physician, is responsible for follow up, contact various caregivers and the development of strategies to minimise suffering. The depressed older persons' needs were complex and therefore influence, creativity and, on occasions, willingness to take unusual initiatives on the part of coordinator were valuable abilities. Above all the coordinator should be available and invite the older person to a dialogue about what she/he needs in order to feel safe, which is essential for achieving better health in elderly individuals [36]. It has long been known that depressed older persons fail to improve because they are mainly treated in primary care settings [5] [6]. In Norway, there was political commitments in mental health in the period 2001-2009 [37] aimed at improving and up-grading services. Although the present evaluation revealed several successful outcomes, cooperation between primary care and specialist psychiatric care was described as inflexible and in need of further improvement. In addition, depressed older persons constituted a group for which there were no health service improvements and therefore require special attention [38]. The results of this study reveal that there is still a need for access to health services, improved coordination and standardized collaboration between multiple caregivers, which calls for a re-design of the health services.

In the present study, Learning skills to better deal with problems, Support to address emotional pain and Experiences of trust and hope were linked to self-management support in the CCM. According to Holm \& Severinsson [19], there is a need to increase patients' self-management in order to improve the quality of care. Healthcare professionals must deepen their understanding of the values inherent in self-management and how it can be implemented to provide encouragement and empowerment [18]. In the literature, core elements of selfmanagement are referred to as strengthening optimism, control, well-being and the pathways that lead to recovery [19]. The participants wanted to learn skills to better handle problems. One of the problems most frequently mentioned in the interviews was family conflicts. While it can be questioned whether the health services are responsible for providing support in such conflicts, the family nevertheless plays an important role in the life of elderly depressed persons [12]; positive family relationships can improve mental ill-health, while support from family members often facilitates recovery [39].

The participants' expectations of being considered capable and valuable are fundamental for productive interactions, while Robinson et al. [8] and Zeng et al. [10], stated that mental ill-health itself leads to negative views of oneself. Feelings such as uselessness and shame were reported, while lack of respect and understanding reinforces negative thinking and could be an explanation for the failure of older persons to improve despite receiving treatment for depression. The findings demonstrate how Being taken seriously and Being involved in decision-making made a remarkable impression on the participants. They provide evidence of the fact that depressed older persons want to be informed, active and involved in decision-making. Their wish to play a role in their care should be considered a resource. In their study, Allan \& Dixon [11] found that the feeling of being met with understanding enables depressed older persons to connect with others, thus preventing withdrawal.

The findings revealed that certain needs were not met by the health services and that participants were still dissatisfied with their life situation. However, in some cases there was an indication of quality improvement related to central components of the CCM. The various components have been widely adopted and evaluated, with results demonstrating that the model improves patient care and clinical outcomes as well as reducing care utilization and costs [40] [41]. There are no available guidelines available on how to effectively operationalize the CCM components in different settings [42]. A recent systematic review by Kadu and Stolee [43] reported the facilitators and barriers encountered during implementing of the CCM in various primary care settings. The review identified themes related to the context of the organisation, the implementation process and individual 
healthcare providers characteristics. These included the culture of the organisation, its structural characteristics, networks and communication, implementation climate and readiness, supportive leadership as well as provider attitudes and beliefs. CCM implementation barriers and facilitators specific to depression management were identified in the systematic review by Holm \& Severinsson [44]. The barriers found were the absence of organisational, administrative and professional ability to implement the CCM, in addition to a lack of clarity pertaining to the care managers' responsibility for promoting patients' self-management ability. Leadership support and vision as well as redesign of the delivery system were reported to be facilitators of success. Holm \& Severinsson [22] [23] found similar barriers to and facilitating factors when they interviewed the healthcare team members after implementation of the CCM, including lack of knowledge about evidence based care, limited responsibility for decision making on individual level and team level, but most especially the absence of effective team leadership in the community. Implementation and changing existing practice are complex processes and require skilled healthcare leaders to monitor them [45]. The individual healthcare professional's knowledge, attitudes, performance and ability to improve practice is also of importance [44]. In order to gain a better understanding of organisational and healthcare professionals' perspectives, assessment of organisational capacity and needs is essential prior to and during and during the implementation of CCM interventions [43].

\section{Conclusion}

The findings highlight the need for healthcare services designed for patients with chronic ill-health. The CCM could serve as a framework for policy change and support the redesign of the existing healthcare system. The development of coordinated actions at different levels is of utmost importance for increasing the health resources of depressed elderly patients, thus enabling them to achieve independence and well-being.

\section{Competing Interests}

The authors declare that there is no conflict of interest.

\section{Acknowledgements}

This research was funded by grants from the Research Council of Norway, "Chronic Disease Management - Implementation and Coordination of Healthcare Systems for Depressed Elderly Persons” (NFR, No. 204238/V50). We would like to thank Gullvi Nilsson and Monique Federsel for reviewing the English language. We also thank Professor Sture Åström for comments on the manuscript.

\section{References}

[1] World Health Organization (2012) Depression Is a Common Illness and People Suffering from Depression Need Support and Treatment. http://www.who.int/mediacentre/news/notes/2012/mental health day 20121009/en/

[2] World Health Organization (2004) Global Burden of Disease. http://www.who.int/healthinf/global_burden_disease/GBD_report_2004update_full.pdf

[3] Sirey, J.A., Bruce, M.L. and Alexopoulous, G.S. (2005) The Treatment Initiation Program: An Intervention to Improve Depression Outcome in Older Adults. American Journal of Psychiatry, 162, 184-186. http://dx.doi.org/10.1176/appi.ajp.162.1.184

[4] Drayer, R., Mulsant, B., Lenze, E., Rollman, B.L., Dew, M.A., Kelleher, K., Karp, J.F., Begely, A., Schulberg, H. and Reynolds, C.F. (2005) Somatic Symptoms of Depression in Elderly Patients with Medical Comorbidities. International Journal of Geriatric Psychiatry, 20, 973-982. http://dx.doi.org/10.1002/gps.1389

[5] Hitchcock, N.P., Williams, J., Unützer, J., Worchel, J., Shuko, L., Cornell, J., Katon, W., Harpole, L. and Hunkler, E. (2004) Depression and Comorbid Illness in Elderly Primary Care Patients: Impact on Multiple Domains of Health Status and Well-Being. Annals of Family Medicine, 2, 555-562. http://dx.doi.org/10.1370/afm.143

[6] Callahan, C. (2001) Quality Improvement Research on Late Life Depression in Primary Care. Medical Care, 39, 722784. http://dx.doi.org/10.1097/00005650-200108000-00004

[7] Djernes, J.K. (2006) Prevalence and Predictors of Depression in Populations of Elderly: A Review. Acta Psychiatrica Scandinavia, 113, 372-387. http://dx.doi.org/10.1111/j.1600-0447.2006.00770.x

[8] Robinson, W.D., Bischoff, R., Geske, J. Backer, E., Olson, M., Jarzynka, K. and Swinton, J. (2012) Rural Experiences with Mental Illness: Through the Eyes of Patients and their Families. Families, Systems, \& Health, 30, 308-321. 
http://dx.doi.org/10.1037/a0030171

[9] Holm, A.L., Lyberg, A. and Severinsson, E. (2014) Living with Stigma: Depressed Elderly Persons' Experiences of Physical Health Problems. Nursing Research and Practice, 2014, Article ID: 527920. http://dx.doi.org/10.1155/2014/527920

[10] Zeng, W., North, N. and Kent, B. (2012) A Framework to Understand Depression among Older Persons. Journal of Clinical Nursing, 21, 2399-2409. http://dx.doi.org/10.1111/j.1365-2702.2011.04049.x

[11] Allan, J. and Dixon, A. (2009) Older Women’s Experiences of Depression: A Hermeneutic Phenomenological Study. Journal of Psychiatric and Mental Health Nursing, 16, 865-873. http://dx.doi.org/10.1111/j.1365-2850.2009.01465.x

[12] Lyberg, A., Holm, A.L., Lassenius, E., Berggren, I. and Severinsson, E. (2013) Older Persons’ Experiences of Depressive Ill-Health and Family Support. Nursing Research \& Practice, 2013, Article ID: 837529. http://dx.doi.org/10.1155/2013/837529

[13] Chew-Graham, C., Kovandžić, M., Gask, L., Burroughs, H., Clarke, P., Sanderson, H. and Dowrick, C. (2012) Why May Older People with Depression Not Present to Primary Care? Messages from Secondary Analysis of Qualitative Data. Health \& Social Care in the Community, 20, 52-60. http://dx.doi.org/10.1111/j.1365-2524.2011.01015.x

[14] Fixsen, D.L., Blasé, K.A., Naoom, S.F. and Wallace, F. (2009) Core Implementation Components. Research on Social Work Practice, 19, 531-540. http://dx.doi.org/10.1177/1049731509335549

[15] World Health Organization (2008) Caring for People with Chronic Conditions: A Health System Perspective. http://apps.who.int/iris/bitstream/10665/112830/1/9789241506793_eng.pdf?ua=1

[16] Bodenheimer, T., Wagner, E.H. and Grumbach, K. (2002) Improving Primary Care for Patients with Chronic Illness. The Chronic Care Model. The Journal of the American Medical Association, 288, 1775-1779. http://dx.doi.org/10.1001/jama.288.14.1775

[17] Bodenheimer, T., Wagner, E.H. and Grumbach, K. (2002) Improving Primary Care for Patients with Chronic Illness. The Chronic Care Model, Part 2. The Journal of the American Medical Association, 288, 1909-1914. http://dx.doi.org/10.1001/jama.288.15.1909

[18] Wagner, E.H., Glasgow, R.E., Davis, C., Bonomi, A.E., Lloyd, P., McCulloch, D., Carver, P. and Sixta, C. (2001) Quality Improvement in Chronic Illness Care: A Collaborative Approach. Joint Commission Journal on Quality Improvement, 27, 63-80.

[19] Holm, A.L., Lyberg, A., Lassenius, E., Berggren, I. and Severinsson, E. (2013) Older Persons’ Lived Experiences of Depression and Self-Management. Issues in Mental Health Nursing, 34, 757-764. http://dx.doi.org/10.3109/01612840.2013.809829

[20] Holm, A.L., Lyberg, A., Berggren, I., Cutcliffe, J. and Severinsson, E. (2014) Shadows from the Past-The Situated Meanings of Being Suicidal among Depressed Older People Living in the Community. Crisis: The Journal of Crisis Intervention and Suicide Prevention, 35, 253-260. http://dx.doi.org/10.1027/0227-5910/a000259

[21] Holm, A.L. and Severinsson, E. (2014) Surviving Depressive Ill-Health: A Qualitative Systematic Review of Older Person's Narratives. Nursing \& Health Sciences, 16, 131-140. http://dx.doi.org/10.1111/nhs.12071

[22] Holm, A.L. and Severinsson, E. (2013) Interdisciplinary Team Collaboration during Discharge of Depressed Older Persons: A Norwegian Qualitative Implementation Study. Nursing Research and Practice, 2013, Article ID: 794743. http://dx.doi.org/10.1155/2013/794743

[23] Holm, A.L. and Severinsson, E. (2014) Perceptions of the Need for Improvements in Healthcare after Implementation of the Chronic Care Model. Nursing \& Health Sciences, 16, 442-448. http://dx.doi.org/10.1111/nhs.12136

[24] Severinsson, E. and Holm, A.L. (2014) Chronic Disease Management: Implementation and Coordination of Healthcare Systems for Depressed Elderly Persons. Issues in Mental Health Nursing, 35, 934-939. http://dx.doi.org/10.3109/01612840.2014.930215

[25] Holm, A.L., Lyberg, A., Berggren, I., Åström, S. and Severinsson, E. (2014) Social Capital and Depressive Ill HealthAn Evaluative Approach to the Implementation of the Chronic Care Model. Open Journal of Nursing, 4, 683-694. http://dx.doi.org/10.4236/ojn.2014.410073

[26] Holm, A.L., Lyberg, A., Berggren, I. and Severinsson, E. (2014) Shared Decision-Making after Implementation of the Chronic Care Model (CCM) - An Evaluative Approach. Open Journal of Nursing, 4, 824-835. http://dx.doi.org/10.4236/ojn.2014.412088

[27] Severinsson, E. and Holm, A.L. (2014) Understanding and Improving Quality of Care in the Context of Depressed Elderly Persons Living in Norway. Open Journal of Nursing, 4, 809-817. http://dx.doi.org/10.4236/ojn.2014.412086

[28] Polit, D.F. and Beck, C.T. (2012) Nursing Research: Generating and Assessing Evidence for Nursing Practice. Lippincott Williams \& Wilkins, London. 
[29] Hsieh, H.F. and Shannon, S.E. (2005) Three Approaches to Qualitative Content Analysis. Qualitative Health Research, 15, 1277-1288.

[30] Graneheim, U.H. and Lundman, B. (2004) Qualitative Content Analysis in Nursing Research: Concepts, Procedures and Measures to Achieve Trustworthiness. Nurse Education Today, 24, 105-112. http://dx.doi.org/10.1016/j.nedt.2003.10.001

[31] Sandelowski, M. and Leeman, J. (2011) Writing Usable Qualitative Health Research Findings. Qualitative Health Research, 22, 1404-1413. http://dx.doi.org/10.1177/1049732312450368

[32] Denzin, N.K. and Lincoln, Y.S. (2008) Collecting and Interpreting Qualitative Materials. Sage, Los Angeles.

[33] Elo, S., Kääriänen, M., Kanste, O., Pölkki, T., Utriainen, K. and Kyngärs, H. (2014) Qualitative Content Analysis: A Focus on Trustworthiness. SAGE Open, 4, 1-10. http://dx.doi.org/10.1177/2158244014522633

[34] World Medical Association (2014) http://www.wma.net/en/30publications/10policies/b3/

[35] Liamputtong, P. (2007) Researching the Vulnerable: A Guide to Sensitive Research Methods. Sage Publisher, London.

[36] Laister, S. (2011) Older Adults' Perceptions of Feeling Safe in an Intensive Unit. Journal of Advanced Nursing, 67, 2649-2657. http://dx.doi.org/10.1111/j.1365-2648.2011.05714.x

[37] The Norwegian Social and Health Department (1997-1998) Stortingsproposisjon No. 63: Opptrappingsplan for psykisk helse 1999-2009. Sosial og Helsedepartementet, Oslo.

[38] The Norwegian Research Council (2009) Evaluering av opptrappingsplanen for psykisk helse (2001-2009). Sluttrapportsyntese og analyse av evalueringens delprosjekter.

[39] Ahlström, B.H., Skärsäter, I. and Danielsson, E. (2009) Living with Major Depression: Experiences from Families’ Perspectives. Scandinavian Journal of Caring Sciences, 23, 309-316. http://dx.doi.org/10.1111/j.1471-6712.2008.00624.x

[40] Coleman, K., Austin, B.T., Brach, C. and Wagner, E.H. (2009) Evidence on the Chronic Care Model in the New Millennium. Health Affairs, 28, 75-85. http://dx.doi.org/10.1377/hlthaff.28.1.75

[41] Dorr, D.A., Wilcox, A., Burns, L., Brunker, C.P., Narus, S.P. and Clayton, P.D. (2006) Implementing a Multidisease Chronic Care Model in Primary Care Using People and Technology. Disease Management, 9, 1-15. http://dx.doi.org/10.1089/dis.2006.9.1

[42] Solberg, L.I., Crain, A.L., Sperl-Hillen, J.M., Hroscikoski, M.C., Engebretson, K.I. and O’Connor, P.J. (2006) Care Quality and Implementation of the Chronic Care Model: A Quantitative Study. Annals of Family Medicine, 4, 310-316. http://dx.doi.org/10.1370/afm.571

[43] Kadu, M.K. and Stolee, P. (2015) Facilitators and Barriers of Implementing the Chronic Care Model in Primary Care: A Systematic Review. BMC Family Practice, 16, 12. http://dx.doi.org/10.1186/s12875-014-0219-0

[44] Holm, A.L. and Severinsson, E. (2012) Chronic Care Model for the Management of Depression: Synthesis of Barriers to, and Facilitators of Success. International Journal of Mental Health Nursing, 21, 513-523. http://dx.doi.org/10.1111/j.1447-0349.2012.00827.x

[45] Craig, P., Macintyre, S., Michie, S., Nazareth, I. and Petticrew, M. (2008) Developing and Evaluating Complex Interventions: The New Medical Research Council Guidance. British Medical Journal, 337, a1655. 